\title{
Senior High School Students' Self-Efficacy and its Relation to Engagement in Online Class Setting in a Private University in the South of Metro Manila
}

\author{
Dionafer Bangga* \\ Department of Science Education, Br. Andrew Gonzalez FSC College of Education, De La Salle University, Manila, Philippines \\ *Corresponding Author: dionafer_bangga_b@dlsu.edu.ph
}

\section{ABSTRACT}

This study explored the self-efficacy of senior high school Science, Technology, Engineering, and Mathematics $(\mathrm{STEM})$ students $(\mathrm{n}=134)$ in an online physics class in terms of gender and its relationship to engagement. The study employed a descriptive correlation research design. Adapted instruments namely "Sources of Self-Efficacy in Science Course - Physics" (SSSCP) and "Engagement in Physics Scale" (EPS) were used to collect the data from the students. SSSCP was correlated with the scores of "Self-Efficacy for Academic Milestone-Strength" scale for its validity. Reliability and validity of EPS was examined through Cronbach alpha and confirmatory factor analysis with acceptable results. Mean and standard deviation were used to answer the research questions while independent samples t-test, Cohen's d, and Pearson r correlation were used to test the hypotheses. It was revealed that both male and female students have a high level of self-efficacy in the following: overall, vicarious experience, verbal persuasion, and performance accomplishment with an average level for the emotional arousal (EA). Furthermore, a significant difference across gender was found only on the EA sub-level with a small effect size of 0.32 . Moreover, positive correlation was found between overall self-efficacy and overall engagement as well as on cognitive engagement. On the other hand, a negative correlation was revealed between overall self-efficacy and emotional engagement. Focusing on increasing the self-efficacy of students in an online physics class should be practiced by teachers in order to increase engagement.

KEY WORDS: engagement; gender difference; online physics class; self-efficacy

\section{INTRODUCTION AND LITERATURE REVIEW}

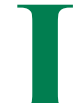

n March of 2020, the World Health Organization proclaimed COVID-19 as a pandemic. This led to many countries going into a lockdown which forced their education sectors to halt face-to-face classes and shift to an online delivery of classes. Given the said mode of learning, it is valuable to investigate the learning process of the students during synchronous and asynchronous classes. Studies on the learning process of the students in the said mode of learning are scarce (Aguilera-Hermida, 2020). This study investigated the self-efficacy of students in the said context across gender and their relationship to engagement which is an intrinsic part of the learning process (Boekaerts, 2016).

Self-efficacy (Bandura, 1977) is the belief of an individual that they can succeed in any given situation and that effort will be exerted to achieve the desired result. It comes from both personal experience and social interactions. The following are the sources of self-efficacy:

1. Performance accomplishment (PA) - Repeated success can improve self-efficacy, whereas repeated disappointment can reduce it
2. Vicarious experience-The observer would believe that if others can do it, he can also do it and will result to increased self-efficacy. Seeing others fail in a certain task will likewise decrease the self-efficacy of the observer

3. Verbal persuasion - influenced by verbally encouraging or discouraging a person in connection to performing a certain task

4. Emotional arousal (EA) - The more at ease an individual is in doing a certain task, the more he would believe that he is competent in doing that task.

These sources of self-efficacy are the same whether the students are in a traditional or online class setting as reported in the study conducted by Lin et al. (2013).

It was confirmed through separate investigations done by Britner and Pajares (2005) and Kiran and Sungur (2011) that each of these sources correlated significantly particularly with middle school students' self-efficacy in the science domain. This indicates that it is valid to analyze self-efficacy of students through its sources. Although, it was emphasized by Zimmerman (2000) and Stewart et al. (2020) that self-efficacy is multidimensional and should be examined on a domain 
Science, Technology, Engineering, and Mathematics (STEM) specific; meaning a gauge of science self-efficacy could be different with physics self-efficacy.

Science self-efficacy across gender was found to not have a significant difference in middle school students (Britner and Pajares, 2005; Kiran and Sungur, 2011). However, broader studies conducted by several researchers with university students revealed a significant difference across gender when examined in a specific domain which is physics (Whitcomb et al., 2019; Stewart et al., 2020).

Bandura (1977) described self-efficacy to be related to engagement. He argued that learners with high self-efficacy have higher engagement during the learning process. This concept was reinforced by Ouweneel et al. (2011) and Chang (2015) who described the correlation between self-efficacy and engagement as positive. Aside from these, there were also other investigations that concluded the same (Guneri and Guvenc, 2013; Birgin et al., 2017; Grant, 2017; Wang et al., 2017).

Research on students' engagement has greatly increased over the last two decades because of the fact that it was found to be a factor of desired student outcome (Pavlin-Bernardić et al., 2017). Student engagement is defined by Trowler (2010) as being:

Concerned with the interaction between the time, effort, and other relevant resources invested by both students and their institutions intended to optimize the students experience and enhance their learning outcomes and development of students and the performance, and reputation of the institution. (p. 2)

Engagement is a multidimensional construct (Trowler, 2010; Axelson and Flick, 2011; Reeve, 2012; Pavlin-Bernardić et al., 2017). It is composed of three dimensions, namely:

1. Cognitive - is how invested a student is to learning or seeking information, as well as storing and using it. Students who are cognitively engaged will seek more than what is required and enjoys information challenge

2. Behavioral - is following behavioral norms such as but not limited to non-disruptive behaviors during classes, high task attention, and persistence

3. Emotional - is the manifestation of task-related positive emotions when engaged such as enjoyment and interest and negative emotions such as anxiety and anger when not engaged.

These components of engagement are said to be unique but not purely independent from one another (Schmidt et al., 2017). An example is a student who is behaviorally engaged (with proper behavior norms) may not be emotionally or cognitively engaged. It was reported that self-efficacy is positively related to cognitive, behavioral, and emotional components of engagement (Linnenbrink and Pintrich, 2003; Kanaparan et al., 2019).

Research in engagement specifically for the science domain is limited but has noted that students have low science engagement which tends to decline at the end of the year according to Schmidt et al. (2017). They also stated that engagement just like self-efficacy is also domain-specific. With this, it should also be examined specifically in the domain of physics to determine if it will also have the same result as the science domain.

The ultimate goal of education is for learners to be successful in a given learning domain which will be indicated through a positive learning outcome or achievement. Self-efficacy and engagement are under the learning process which affects learning outcomes (Boekaerts, 2016). It was found out that self-efficacy and engagement individually contributed to a positive learning outcome (Lavasani et al., 2009; Ucar and Sungur, 2017; Nese, 2019). This shows how important it is to investigate these aspects of learning process.

Taking into consideration these previous studies which were done in a traditional class setting, the researcher used these as a benchmark to develop the present study in the context of an online class specifically in physics domain.

\section{Statement of the Problem}

The objective of this study was to determine the levels of sources of self-efficacy of the students as well as its implication, if there were significant differences in the self-efficacy of the students across gender, and if self-efficacy was significantly related to engagement.

Specifically, it sought to address the question:

1. What are the levels of sources of self-efficacy and what does it imply?

And tested the following hypotheses in the context of general physics 1 subject:

1. There is no significant difference between the sources of self-efficacy of male and female senior high school students

2. There is no significant relationship between students' self-efficacy and engagement.

\section{METHODS}

The study was quantitative and employed the correlation design. Purposive sampling was used in determining the research participants which was the Grade12 STEM $(n=200)$ students from a private university who took online General Physics 1 class. Out of the initial responses, the valid responses which contained answers for both surveys were $\mathrm{n}=134$ which was comprised of 68 male and 66 female students.

The data collection tools comprised the "Sources of Self-Efficacy in Science Course-Physics" and the "Engagement in Physics Scale." The "Sources of Self-Efficacy in Science Course" is a 33-item Likert-type scale instrument which was developed by Fencl and Scheel (2005) to investigate the sources of self-efficacy specifically in the context of Physics. The total internal consistency reliability was established through the use of Cronbach alpha which was 0.94 and for the subscale ranging from 0.68 to 0.88 . As for the validity, it was correlated with the scores on the "Self- Efficacy for 
Academic Milestones-Strength" scale (Brown et al., 1989) which was a recognized global self-efficacy scale for science and engineering. The instrument was altered to some degree so that it would suite the context of the participants. For example, the word "course" was changed to "subject," as in General Physics 1.

The study adapted the "Engagement in Physics Scale" which was constructed by Pavlin-Bernardić et al. (2017) guided by the three-component conception of engagement (Fredricks et al., 2004). It is an 18 - item Likert-type scale with 1 as Strongly Disagree and 5 as Strongly Agree. It is divided into three components, namely cognitive, behavioral, and emotional engagement. Behavioral and emotional engagement on the survey portray negative statements, meaning the higher the mean of any of this equate to higher disagreement of the students to these negative statements (five pertains to Strongly Disagree and one pertains to Strongly Agree). Validity and reliability of the instrument were tested through confirmatory factor analysis and Cronbach alpha which revealed acceptable values. Statement number 6 of the "Engagement in Physics Scale" was slightly modified to fit into the context of online class. Instead of the statement "chat with a neighboring classmate," it was changed to "exchange messages with classmates."

Data collection comprised three stages: pre-administration of questionnaires, administration of questionnaires, and results collection and analysis. The researcher secured a permit from the principal of the senior high school department and informed consent from the students. After which was the administration of the questionnaires. When the permission was obtained, the researcher proceeded to orient the students about the aim of the study and data collection. Then, two online survey questionnaires namely "Sources of Self-Efficacy in Science Course - Physics" and "Engagement in Physics Scale" were given to the participants through google form which included the consent form. This was given and collected after the end of the subject, General Physics 1, $1^{\text {st }}$ semester of the 2020-2021 school year. Results collection and analysis followed after the participants answered the google forms, the data were retrieved into an excel file. Data of participants who only answered one survey were removed, only those who were able to respond to both were used for the analysis.

\section{Data Analysis}

Mean and standard deviation were used to describe the levels of self-efficacy of the students while inferential statistics such as independent samples t-test, Cohen's d, and Pearson $\mathrm{r}$ correlation were used to test for the significant difference across gender and relationship of self-efficacy and engagement. Assumptions for using the said inferential statistics were examined before conducting the test. Test of normality and the appropriate type of data were all met.

The mean scores of the sources of self-efficacy of male and female students were used to conduct an independent samples t-test. Assumptions of the t-test were checked first before proceeding the computation. The normality of each of the sources of self-efficacy and the overall were assessed through conducting histogram on IBM SPSS version 20. The results showed approximately normal distribution for each of the variables. For the level of measurement, it obeys the independent categorical variable and dependent continuous variable. In this study, the results from the Likert scale were treated as a continuous data since mean score were computed for each.

Pearson r-correlation was used to establish if there is a significant relationship between overall self-efficacy and components of engagement as well as the overall. To technically apply this statistical tool, normality of the variables should be established. Histogram results for each of the said variables from SPSS showed that each of the variable are approximately normally distributed.

\section{FINDINGS AND DISCUSSIONS}

Students' self-efficacy during General Physics 1 online class from different sources as well as the overall were compared across gender as reflected in Table 1 .

Each of the means was given its verbal equivalence as presented in Table 2. Vicarious learning, verbal encouragement, PAs, and overall self-efficacy were all described as high level of sources of self-efficacy on both gender while the only source of self-efficacy which revealed to be average in level is the EA on gender as well.

Table 1: Sources of self-efficacy across gender

\begin{tabular}{lcccc}
\hline Sources of self-efficacy & Gender & Mean & SD & Level of sources of self-efficacy gained \\
\hline Emotional arousal & Male & 3.35 & 0.60 & Average \\
& Female & 3.08 & 0.61 & Average \\
Vicarious learning & Male & 3.56 & 0.53 & High \\
& Female & 3.46 & 0.59 & High \\
Verbal encouragement & Male & 3.78 & 0.51 & High \\
& Female & 3.88 & 0.52 & High \\
Performance accomplishments & Male & 3.56 & 0.57 & High \\
Overall self-efficacy & Female & 3.50 & 0.58 & High \\
& Male & 3.56 & 0.47 & High \\
\hline
\end{tabular}




\begin{tabular}{lc}
\hline $\begin{array}{l}\text { Table 2: Reference table for self-efficacy level } \\
\text { interpretation }\end{array}$ \\
\hline Verbal Interpretation & Score interval \\
\hline Very low & $1.00-1.79$ \\
Low & $1.80-2.59$ \\
Average & $2.60-3.39$ \\
High & $3.40-4.19$ \\
Very high & $4.20-5.00$ \\
\hline
\end{tabular}

The level of the sources of self-efficacy of male and female participants was found to be equal in all the five variables, where vicarious learning, verbal encouragement, PAs, and overall self-efficacy had high levels while EA was a medium level. These results imply that the students were given equal opportunity to acquire and develop their self-efficacy in the said different sources even in an online setting which was also in agreement with the study of Britner and Pajares (2005), and Kiran and Sungur (2011). Furthermore, according to Bandura (1997), high level in vicarious learning means that the students view the accomplishments of their classmates as a positive thing and that they could later also do which will result to higher self-efficacy. This is a good thing, especially in a physics class which is perceived to be a difficult subject by most of the students. Having a good source of vicarious learning aspect of self-efficacy also implies that there are students who were still able to succeed in a physics class given the challenges in an online setting. On the high level of verbal encouragement, this result suggests that the physics online class had a kind of environment where students were given compliments and encouragement which made them to develop this aspect of self-efficacy. For the high level of PA, it reveals a positive implication that students experience higher level of success in physics class even in an online setting instead of experiencing failure. With these, it was also found out that the high level of overall self-efficacy was developed by the students which gives a general idea that the conduct of the online physics class fostered a good source of self-efficacy. However, it was also noted that the medium level of EA was gained by the students. This shows that the students had negative and positive emotions during the conduct of online class.

\section{Gender Difference in Sources of Self-Efficacy}

Table 3 reveals that only the EA source of self-efficacy differs significantly for male $(\mathrm{M}=3.35, \mathrm{SD}=0.60)$ and female $(\mathrm{M}=3.08, \mathrm{SD}=0.61)$ participants; $\mathrm{t}(132), \mathrm{p}=0.01$. The effect size was 0.32 as calculated using Cohen's d which is described to be a small effect. Furthermore, vicarious learning did not differ significantly for male $(\mathrm{M}=3.56, \mathrm{SD}=0.53)$ and female $(\mathrm{M}=3.46, \mathrm{SD}=0.59)$ participants, $\mathrm{t}(132)=2.63$, $\mathrm{p}=0.33$; verbal encouragement did not differ significantly for male $(\mathrm{M}=3.78, \mathrm{SD}=0.51)$ and female $(\mathrm{M}=3.88, \mathrm{SD}=0.52)$ participants, $\mathrm{t}(132)=-1.16, \mathrm{p}=0.25$; PAs did not differ significantly for male $(\mathrm{M}=3.56, \mathrm{SD}=0.57)$ and female $(\mathrm{M}=3.50, \mathrm{SD}=0.58)$ participants, $\mathrm{t}(132)=0.60, \mathrm{p}=0.55$; and overall self-efficacy did not differ significantly between males $(\mathrm{M}=3.56, \mathrm{SD}=0.47)$ and females $(\mathrm{M}=3.49, \mathrm{SD}=0.48)$ despite gaining high level for each.

The conduct of independent samples t-test presented that vicarious learning, verbal encouragement, PAs, and overall self-efficacy were not significantly different across the genders. However, a significant difference was found across gender on the EA source of self-efficacy. The insignificant difference across gender on the said variables is contrary to what most of the literature on similar studies reveal while the significant difference across gender on EA revealed similar results (Lindstrøm and Sharma, 2006; Vashti, 2011; Espinosa et al., 2019; Nissen, 2019; Whitcomb et al., 2019; Kalender et al., 2020; Stewart et al., 2020). The significant difference between male and female students on physics self-efficacy which was explained through several studies was primarily because of stereotyping, where physics is perceived to be a subject for male students. If the idea of stereotyping exists in a physics class environment, there would be a prior thought on the mind of the students that they have greater or less capability than each other. The result of this study uncovers the idea that in a physics online class setting on most of the sources of self-efficacy the perceived idea of stereotyping

Table 3: t-test values for sources of self-efficacy and gender

\begin{tabular}{|c|c|c|c|c|c|c|c|}
\hline \multirow[t]{3}{*}{ Sources of self-efficacy } & \multicolumn{2}{|c|}{$\begin{array}{l}\text { Levene's test } \\
\text { for equality of } \\
\text { variances }\end{array}$} & \multicolumn{5}{|c|}{$\mathrm{T}$ test for equality of means } \\
\hline & \multirow[t]{2}{*}{$\mathbf{F}$} & \multirow[t]{2}{*}{ Sig. } & \multirow[t]{2}{*}{$t$} & \multirow[t]{2}{*}{ df } & \multirow[t]{2}{*}{ Sig. (2-tailed) } & \multicolumn{2}{|c|}{$\begin{array}{l}\text { 95\% confidence } \\
\text { interval of the } \\
\text { difference }\end{array}$} \\
\hline & & & & & & Lower & Upper \\
\hline Emotional arousal & 1.16 & 0.28 & 2.63 & 132 & $0.01 *$ & 0.07 & 0.47 \\
\hline Vicarious learning & 1.88 & 0.17 & 0.98 & 132 & 0.33 & -0.10 & 0.59 \\
\hline Verbal encouragement & 0.21 & 0.65 & -1.16 & 132 & 0.25 & -0.28 & 0.07 \\
\hline $\begin{array}{l}\text { Performance } \\
\text { accomplishments }\end{array}$ & 0.25 & 0.62 & 0.60 & 132 & 0.55 & -0.14 & 0.26 \\
\hline Overall self-efficacy & 0.59 & 0.44 & 0.88 & 132 & 0.38 & -0.09 & 0.23 \\
\hline
\end{tabular}

$* \rho<0.05$, two-tailed 
which is present in a traditional physics class setting is low to none. The significant difference across gender on EA is similar to the result found by Kiran and Sungur (2011), although, in their study, the female students had a higher source of EA compared to male students which is opposite to the result of this study. With this, it can be concluded that male students in a physics online class have a stronger EA source of self-efficacy. Meaning that they tend to have more positive emotion as feedback to challenges in a physics online class setting. They also manage their negative emotions well compared to female students. However, this difference had a small effect size as presented by the result of computing Cohen's d.

\section{Relationship of Self-efficacy and Components of Engagement}

The result of the correlation is presented in Table 4.

To describe the strength of association between self-efficacy and engagement, the guidelines as shown in Table 5 were used.

The results revealed that the overall self-efficacy was positively related with cognitive, $\mathrm{r}=0.53, \mathrm{n}=134, \rho=0.000$; and overall engagement, $r=0.20, \rho=0.018$ while overall self-efficacy was negatively related with emotional engagement, $r=-0.19$, $\rho=0.027$. However, there was no correlation found between self-efficacy and behavioral engagement, $r=0.04, \rho=0.661$.

Results showed that there was a positive correlation between overall self-efficacy and cognitive and overall engagement, a negative correlation with emotional engagement, and no significant relationship with behavioral engagement. These results were aligned to existing literature on similar studies (Bandura, 1977; Linnenbrink and Pintrich, 2003; Ouweneel et al., 2011; Guneri and Guvenc, 2013; Chang, 2015; Birgin et al., 2017; Grant, 2017; Wang et al., 2017; Kanaparan et al., 2019). Specifically, the results suggest that the higher the self-efficacy of the students,

\begin{tabular}{lcccc}
\hline $\begin{array}{l}\text { Table 4: Correlation values of self-efficacy and } \\
\text { engagement }\end{array}$ \\
\hline \multicolumn{4}{c}{ Description } & \multicolumn{4}{c}{ Engagement } \\
\cline { 2 - 5 } & Cognitive & Behavioral & Emotional & Overall \\
\hline Overall self-efficacy & & & & \\
Pearson correlation & $0.53^{*}$ & 0.04 & $-0.19^{*}$ & $0.20^{*}$ \\
Sig. (2-tailed) & 0.000 & 0.661 & 0.027 & 0.018 \\
Strength of association & Large & None & Small & Small \\
\hline$* \rho<0.05$, two-tailed & & & & \\
\end{tabular}

Table 5: Reference table for strength of association of self-efficacy and engagement

\begin{tabular}{lcc}
\hline Strength of association & \multicolumn{2}{c}{ Coefficient, $\mathbf{r}$} \\
\cline { 2 - 3 } & Positive & Negative \\
\hline Small & $0.1-0.3$ & $-0.1-0.3$ \\
Medium & $0.3-0.5$ & $-0.3-0.5$ \\
Large & $0.5-1.0$ & $-0.5--1.0$ \\
\hline
\end{tabular}

the further cognitive engaged the students would be. They tend to persist and give extra effort on learning the physics lessons. The negative relationship between overall self-efficacy and emotional engagement denotes the other way around. Meaning the higher results of emotional engagement means that they did not agree to have such negative emotions during online physics class which is what the result revealed. Moreover, the physics online class environment can also be described to have a positive environment, emotion wise, since the students were at ease during class, tends to enjoy it, and do not feel anxious. Finally, there is no significant relationship between the self-efficacy and behavioral engagement. This may be attributed to the kind of learning environment that the students had which was online, where there was less supervision and higher risk of not listening intently during discussion.

\section{CONCLUSION}

These students' level of sources of self-efficacy in an online general physics 1 class was found to be medium to high level. And a significant difference across gender was found only on the EA component of self-efficacy. Furthermore, it was also revealed that overall self-efficacy is positively related to both overall engagement and cognitive engagement while a negative relationship exists with behavioral engagement.

\section{RECOMMENDATIONS}

Based on the findings of the study, the following recommendations were made:

1. Since there is a limited number of studies on physics self-efficacy and engagement in an online class setting, it is encouraged that research on similar samples locally should be conducted to verify the results of the study

2. Consider the interaction of sources of self-efficacy and components of engagement. Doing this could reveal more interesting implications

3. The study measured only the sources of the physics selfefficacy and engagement of the students at the end of the general physics 1 class. Future researchers can consider getting these before and after the conduct of the course to determine if there is a significant difference on the variables on the said periods.

\section{ACKNOWLEDGMENT}

This study was made possible because of the scholarship grant of the Department of Science and Technology - Science Education Institute.

\section{REFERENCES}

Aguilera-Hermida, P.A. (2020). College students' use and acceptance of emergency online learning due to COVID-19. International Journal of Educational Research Open, 1, 100011.

Axelson, R., \& Flick, R. (2011). Defining student engagement. Change: The Magazine of Higher Learning, 43(1), 38-43.

Bandura, A. (1977). Self-efficacy: Toward a unifying theory of behavioral 
change. Psychological Review, 84(2), 191-215.

Bandura, A. (1997). Self-efficacy: The Exercise of Control. United States: W.H. Freeman.

Birgin, O., Mazman-Akar, S.G., Uzun, K., Goksu, B., Peker, E.S., \& Gumus, B. (2017). Investigation of factors affected to Mathematics engagement of middle school students. International Online Journal of Educational Sciences, 9(4), 1093-1110.

Boekaerts, M. (2016). Engagement as an inherent aspect of the learning process. Learning and Instruction, 43, 76-83.

Britner, S., \& Pajares, F. (2005). Sources of science self-efficacy beliefs of middle school students. Journal of Research in Science Teaching, 43(5), 485-499.

Brown, S.D., Lent, R.W., \& Larkin, K.C. (1989). Self-efficacy as a moderator of scholastic aptitude-academic performance relationships. Journal of Vocational Behavior, 35(1), 64-75.

Chang, D. (2015). Determining the Relationship Between Academic Selfefficacy and Student Engagement by Metaanalysis. Conference Session. Hong Kong: $2^{\text {nd }}$ International Conference on Education Reform and Modern Management.

Espinosa, T., Miller, K., Araujo, I., \& Eric, M. (2019). Reducing the gender gap in students' physics self-efficacy in a team- and projectbased introductory physics class. Physical Review Physics Education Research, 15(1), 010132.

Fencl, H., \& Scheel, K. (2005). Engaging students: An examination of the effects of teaching strategies on self-efficacy and course climate in a Nonmajors physics course. Journal of College Science Teaching, 35(1), 20-24.

Fredricks, J.A., Blumenfeld, P.C., \& Paris, A.H. (2004). School engagement: Potential of the concept, state of the evidence. Review of Educational Research, 74(1), 59-109.

Grant, T.G. (2017). The Roles of Motivation and Engagement in Students' Academic Achievement at Jamaican Schools. Sydney, Australia: Unpublished Doctoral Thesis, School of Education Faculty of Arts and Social Sciences, The University of New South Wales.

Guneri, E., \& Guvenc, H. (2013). Ilkogretim II. Kademe ogrencilerinin Fen ve Teknoloji dersi oz yeterlik algilari veetkin katılımlari. In: The Secondary School Students' Self-efficacy Perceptions and Engagement and Disaffection in Science and Technology Course. Edirne, Turkey: Unpublished Master Thesis, Trakya University, Institute of Educational Sciences.

Kalender, Y., Marshman, E., Schunn, C., Nokes-Malach, T., \& Singh, C. (2020). Damage caused by women's lower self-efficacy on physics learning. Physical Review Physics Education Research, 16(1), 010118.

Kanaparan, G., Cullen, R., \& Mason, D. (2019). Effect of self-efficacy and emotional engagement on introductory programming students. Australasian Journal of Information Systems, 23, 1825.

Kiran, D., \& Sungur, S. (2011). Middle school students' science self-efficacy and its sources: Examination of gender difference. Journal of Science Education and Technology, 21(5), 619-630.

Lavasani, M., Ejei, J., \& Afshari, M. (2009). The relationship between academic self-efficacy and academic engagement with academic achievement. Journal of Psychology, 13(3), 289-305.

Lin, Y.C., Liang, J.C., Yang, C.J., \& Tsai, C.C. (2013). Exploring middleaged and older adults' sources of Internet self-efficacy: A case study. Computers in Human Behavior, 29(6), 2733-2743.
Lindstrøm, C., \& Sharma, M. (2006). Self-efficacy of first year university physics students: Do gender and prior formal instruction in physics matter? International Journal of Innovation in Science and Mathematics Education, 19(2), 1-19.

Linnenbrink, E., \& Pintrich, P. (2003). The role of self-efficacy beliefs in student engagement and learning in the classroom. Reading and Writing Quarterly, 19(2), 119-137.

Nese, O. (2019). Relationships between self-efficacy beliefs, engagement and academic performance in math lessons. Cypriot Journal of Educational Sciences, 14(2), 190-200.

Nissen, J. (2019). Gender differences in self-efficacy states in high school physics. Physical Review Physics Education Research, 15(1), 013102.

Ouweneel, E., Le Blanc, P.M., \& Schaufeli, W.B. (2011). Flourishing students: A longitudinal study on positive emotions, personal resources, and study engagement. Journal of Positive Psychology, 6(2), 142-153.

Pavlin-Bernardić, N., Putarek, V., Rovan, D., Petričević, E., \& VlahovićŠtetić, V. (2017). Students' engagement in learning physics: A subjectspecific approach. In: Burić, I., (Ed.), $20^{\text {th }}$ Psychology Days in Zadar: Book of Selected Proceedings. Croatia: University of Zadar. pp. 193-203.

Reeve, J. (2012). A self-determination theory perspective on student engagement. In: Christenson, S.L., Reschly, A.L., \& Wylie, C. (Eds.), Handbook of Research on Student Engagement. Germany: Springer. pp. 149-172.

Schmidt, J., Rosenberg, J., \& Berner, P. (2017). A person-in-context approach to student engagement in science: Examining learning activities and choice. Journal of Research In Science Teaching, 55(1), 19-43.

Stewart, J., Henderson, R., Michaluk, L., Deschler, J., Fuller, E., \& RamboHernandez, K. (2020). Using the social cognitive theory framework to chart gender differences in the developmental trajectory of STEM self-efficacy in science and engineering students. Journal of Science Education and Technology, 29: 758-773.

Trowler, V. (2010). Student Engagement Literature Review. England: University of Huddersfield. Available from: https://www.pure.hud. ac.uk/en/publications/student-engagement-literature-review

Ucar, M., \& Sungur, S. (2017). The role of perceived classroom goal structures, self-efficacy, and engagement in student science achievement Research in Science and Technological Education, 35(2), 149-168.

Vashti, S. (2011). A Gender Study Investigating Physics Self-efficacy. United States: FIU Electronic Theses and Dissertations. Number 512. Available from: https://www.digitalcommons.fiu.edu/etd/512

Wang, Y.L., Lin, C.Y., \& Tsai, C.C. (2017). Identifying Taiwanese juniorhigh school students' mathematics learning profiles and their roles in Mathematics learning self-efficacy and academic performance. Learning and Individual Differences, 54, 92-101.

Whitcomb, K., Kalender, Y., Nokers-Malach, T., Schunn, C., \& Singh, C. (2019). Inconsistent gender differences in self-efficacy and performance for engineering majors in physics. Physics Education Research Conference Proceedings, 17, 639-644.

World Health Organization. (2020). WHO announces COVID-19 Outbreak A Pandemic. Available from: https://www.euro.who.int/en/health-topics/ health-emergencies/coronavirus-covid-19/news/news/2020/3/whoannounces-covid-19-outbreak-a-pandemic

Zimmerman, B.J. (2000). Self-efficacy: An essential motive to learn. Contemporary Educational Psychology, 25(1), 82-91. 